\title{
Local Climate Zone mapping using GIS methods in Szeged
}

\author{
JÁNos UNGER ${ }^{1}$, ENIKô LELOVICS ${ }^{1}$ and TAMÁs GÁL ${ }^{1}$
}

\begin{abstract}
Owing to anthropogenic activity, local climate develops in the area of built-up zones. The characteristics of built-up zones can be quantified by different methods. One of the methods is the Local Climate Zones (LCZ) classification system which describes the physical conditions of a local-scale environment of a measuring site from the viewpoint of the generated local climate. It is applicable worldwide universally and relatively easily based on objective geometric, radiative and thermal properties of the surface. The objectives of this study are to develop GIS methods in order to calculate several parameters describing the LCZs for any part of the study area using different databases and to identify and delineate the LCZ types which occur in and around the city of Szeged (Hungary) using the developed methods. As a result, six built LCZ types were distinguished and mapped in the studied urban area: "compact mid-rise", "compact low-rise", "open mid-rise", "open low-rise", "large low-rise" and "sparsely built". The developed method can be used in any urban area if the necessary input databases are available.
\end{abstract}

Keywords: climate mapping, Local Climate Zones, surface parameters, lot area polygons, GIS, Szeged

\section{Introduction}

Nowadays about half of the human population is affected by the burdens of urban environments, therefore studies dealing with the urban impact on climate are particularly important. By definition, the urban climate is a local climate which is modified by the interactions between the built-up area and the regional climate (WMO, 1983). Among the parameters of the urban atmosphere, the near-surface (screen-height) air temperature shows the most obvious modification compared to the rural area. Urban warming is commonly referred to as the urban heat island (UHI) and its magnitude is the UHI inten-

${ }^{1}$ Department of Climatology and Landscape Ecology, University of Szeged, H-6720 Szeged, Aradi vértanúk tere 1. E-mails: unger@geo.u-szeged.hu, lelovics@geo.u-szeged.hu, tgal@geo.u-szeged.hu 
sity (Оке, T.R. 1987). Traditionally, UHI intensity is interpreted and calculated as the difference between the temperature values of a central urban site and those of a nearby rural site.

In the literature of heat island, the terms "urban" and "rural" have no single, objective meaning as the areas around the measuring sites can be very different. For example, an "urban" site can be in a park, college ground, street canyon, housing estate, etc., while "rural" sites are placed e.g. at airports, farmlands, fields or in the suburb areas depending on the investigated cities. It makes difficult to compare the results obtained in the different settlements of the world (Stewart, I.D. 2011).

To improve the characterization of the surrounding environment of the measurement sites based on their ability to influence the local thermal and dynamic conditions of the near-surface atmosphere, Stewart, I.D. and Оке, T.R. (2012) developed a classification system. Their Local Climate Zones (LCZ) system is based on the earlier works of Auer, A.H. (1978), Ellefsen, R. (1991), Оке, T.R. (2004), and STEWART, I.D. and Оке, T.R. (2009) as well as a personal worldwide survey of heat island measurement sites and their local environments (STEWART, I.D. 2011).

The objectives of this paper are

- to develop GIS methods in order to calculate some geometric, surface cover and radiative parameters describing the LCZs for any part of the study area using different databases which are available or created for that purpose,

- to identify and delineate the LCZ types which occur in and around the city of Szeged using the calculated surface parameters by the developed methods.

\section{Short introduction of the LCZ system and the study area}

The main purpose of the LCZ system is to facilitate the characterization of the local environment around a temperature measuring site with a screen-height sensor in terms of its ability to influence the local thermal climate. To this end, the number of types is not too large and the separation is based on objective, measurable parameters. LCZs are defined as "regions of uniform surface cover, structure, material, and human activity that span hundreds of metres to several kilometres on horizontal scale" (STEWART, I.D. and OKe, T.R. 2012). The spatial extension of the zones is local because an upwind fetch of typically 200-500 metres is required for the air at screen-height to become fully adjusted to the underlying, relatively homogeneous surface (Оке, T.R. 2004). The main characteristics of the LCZ types are reflected in their names (Table 1).

LCZ types can be distinguished by typical value ranges of measurable physical properties which characterize the surface geometry and cover, the thermal, radiative and anthropogenic energy features of the surface (Table 2). 
Table 1. Names and codes of the LCZ types

\begin{tabular}{l|l|l|l}
\hline \multicolumn{2}{|l|}{ Built types } & \multicolumn{2}{c}{ Land cover types } \\
\hline LCZ 1 & compact high-rise & LCZ A & dense trees \\
LCZ 2 & compact mid-rise & LCZ B & scattered trees \\
LCZ 3 & compact low-rise & LCZ C & bush, scrub \\
LCZ 4 & open high-rise & LCZ D & low plants \\
LCZ 5 & open mid-rise & LCZ E & bare rock / paved \\
LCZ 6 & open low-rise & LCZ F & bare soil / sand \\
LCZ 7 & lightweight low-rise & LCZ G & water \\
LCZ 8 & large low-rise & & \\
LCZ 9 & sparsely built & & \\
LCZ 10 & heavy industry & & \\
\hline
\end{tabular}

Source: Stewart, I.D. and OKe, T.R. 2012.

Table 2. Physical properties characterizing the elements of the LCZ system

\begin{tabular}{l|l}
\hline \multicolumn{2}{c}{ Types of properties } \\
\hline \multicolumn{1}{c}{ Geometric, surface cover } & \multicolumn{1}{c}{ Thermal, radiative, metabolic } \\
\hline sky view factor & $\begin{array}{l}\text { surface admittance } \\
\text { aspect ratio } \\
\text { suilding surface fraction } \\
\text { pervious surface fraction } \\
\text { impervious surface fraction } \\
\text { anthropogenic heat output } \\
\text { terrain roughness class }\end{array}$ \\
\hline
\end{tabular}

Source: STEWART, I.D. and OKe, T.R. 2012.

The LCZ classification system was not designed specifically for mapping but to standardize the classification of urban heat island observation sites, either urban or rural. Nevertheless, the spatial mapping of the urban terrain is a justifiable use of the system to determine the areas which are relatively homogeneous in surface properties and human activities.

In the context of the new LCZ classification system, the inter-urban UHI intensity is not an "urban-rural" temperature difference, but a temperature difference between the pairs of LCZ types (STEwART, I.D. et al. 2013). In this way, the application of the LCZ system gives an opportunity to compare the thermal reactions of different areas within a city and between cities (intraurban and inter-urban comparisons) objectively.

Szeged as a study area is located in the South-Eastern part of Hungary $\left(46^{\circ} \mathrm{N}, 20^{\circ} \mathrm{E}\right)$ at 79 metres above sea level on a flat terrain with a population of 160,000 within an urbanized area of about $40 \mathrm{~km}^{2}$. The area is in Köppen's climatic region $\mathrm{Cfb}$ with an annual mean temperature of $10.4{ }^{\circ} \mathrm{C}$ and an amount of yearly precipitation of $497 \mathrm{~mm}$. The study area covers a $10 \mathrm{~km} \times 8 \mathrm{~km} \mathrm{rec}-$ tangle in and around Szeged (Figure 1). 


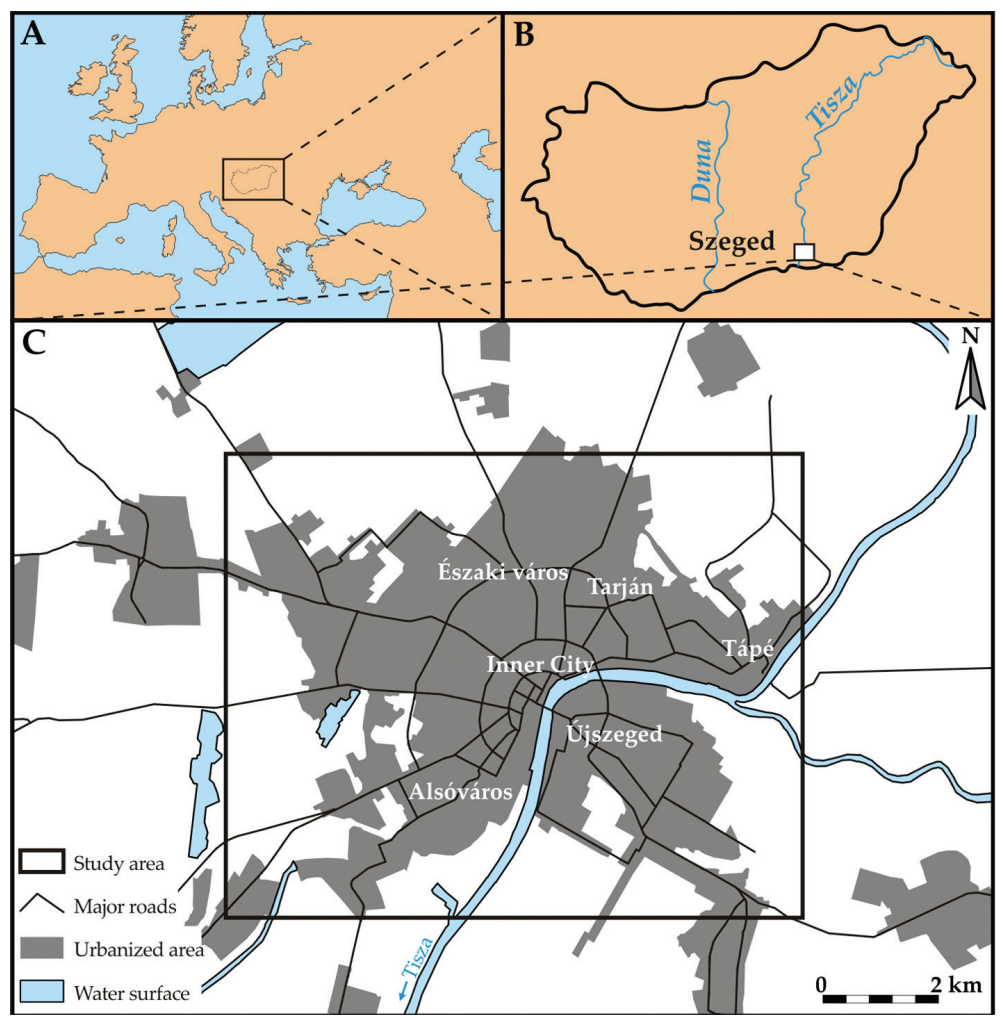

Fig. 1. Location of Szeged in Europe (A) and in Hungary(B) as well as the study area in and around Szeged $(\mathrm{C})$

\section{GIS methods developed for LCZ mapping}

\section{Parameter calculations for lot area polygons}

Using our method we can determine seven properties out of ten listed by Stewart, I.D. and Oke, T.R. (2012) for any given area inside the study area based on the available databases. From the initial parameters, we omitted the aspect ratio since it can be clearly calculated only in the case of the regular street network. The patterns of the surface admittance and the anthropogenic heat output were not available in the study area, either.

During the determination process of the other seven parameters the basic area of the calculation was the building block and the area belonging to it (called lot area polygon, Figure 2). 


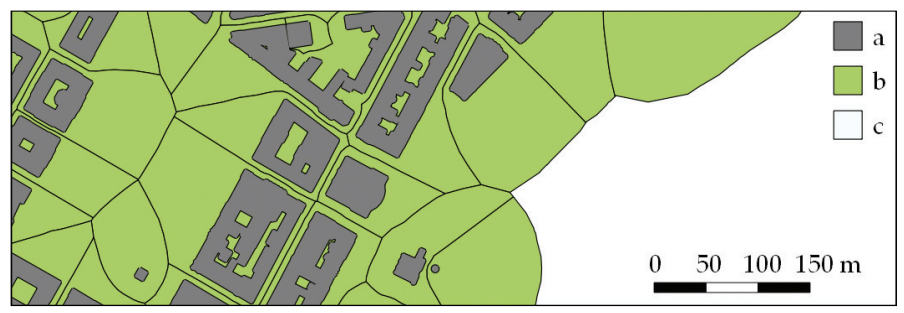

Fig. 2. Examples of lot area polygons in the study area. $-\mathrm{a}=$ building block; $\mathrm{b}=$ lot area polygon; c = open area without buildings

The determination of the building block footprints and lot area polygons is based on the 3D building database of Szeged which contains more than 22,000 individual buildings with building height information in ESRI shape-file format (GÁL, T. and UNGER, J. 2009). The calculation processes, the necessary databases and the outputs are shown in Figure 3.

All of the calculations were carried out with self-developed Fortran algorithms and for the visualization of the outputs, Quantum GIS was used. The calculation methods and the applied databases by parameters were as follows:

- Sky view factor (SVF): The input was a SVF database originated from our earlier studies (e.g. GÁL, T. et al. 2009). During the SVF calculation, each building was considered with flat roofs and the effect of the vegetation was neglected. SVF values refer to the street level and they are averaged inside the polygons.

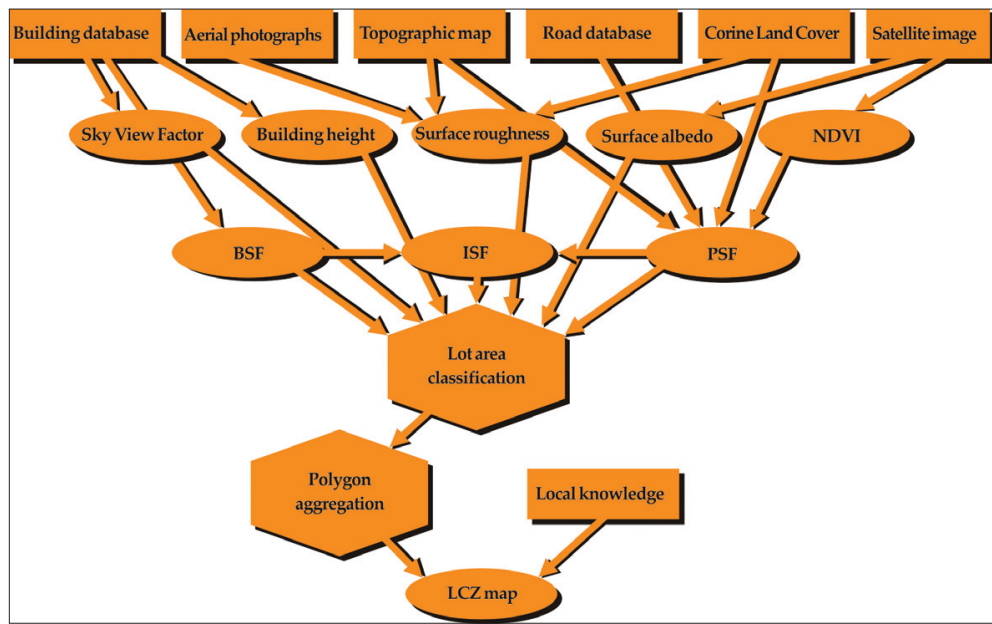

Fig. 3. Flow chart of the automated classification and aggregation of the lot area polygons to determine the appropriate size of $\mathrm{LCZ}$ areas 
- Building surface fraction (BSF): The input was also the 3D building database. BSF is the ratio of the summarized footprint areas and the polygon area.

- Pervious surface fraction (PSF): The input was a built-up dataset calculated from RapidEye (2012) satellite image using NDVI index, a 1:25,000 topographic map, a road database and the Corine Land Cover (CLC) database (Bossard, M. et al. 2000). The RapidEye image (resolution of $5.16 \mathrm{~m}$ ) was atmospherically corrected and the NDVI was calculated using bands 3 and 5 (TuCKER, C.J. 1979), and the points where the NDVI was below 0.3 were regarded as a covered area. The CLC dataset was used to locate the agricultural areas as these areas have small NDVI (like the covered areas) because the amount of plants is negligible after harvest. As a second correction, the shapes of water bodies were digitized from the topographic map because in several cases the water had NDVI values very similar to the values of some building materials. As a last correction, the road database was used to locate the asphalt roads in the area because in the urban canyons asphalt roads are usually under tree cover and the roads which dissect agricultural areas do not appear in CLC dataset.

- Impervious surface fraction (ISF): It is the paved area outside the buildings and it can be calculated as the remnant from the total area, ISF $=1-(\mathrm{BSF}+$ PSF).

- Height of roughness elements (HRE): Using the 3D building database for each area, the building heights were averaged weighted with their footprint areas.

- Terrain roughness class (TRC): For describing the roughness, the Davenport roughness classification method was used (DAVENPORT, A.G. et al. 2000). The widespread method comprises eight classes of roughness. Larger areas were classified into different roughness classes using CLC dataset with the visual interpretation of aerial photographs, the topographical map and the building database.

- Surface albedo (SA): As an input, the atmospherically corrected reflectance values of the 5 band RapidEye satellite image were used. Broadband albedo was calculated as an average of the reflectance values weighted with the integral of the radiation within the spectral range of a given band (STARKS, P.J. et al. 1991; Tasumi, M. et al. 2008).

In order to illustrate the obtained patterns of the calculated parameters with some examples, Figure 4. shows the spatial patterns of two parameters in the study area. Regarding the PSF, the pattern is generally higher on the edge of the city and near the city centre.

The largest parks and green areas of the city (e.g. banks of the Tisza, the forested areas along the circle dam) also appear on the map. In the case of HRE, most of the values are between 10 and 20 metres in the inner part of the city and only a few of them (e.g. church, clinical block, educational centre, theatre) are higher than 30 metres in the Western side of the Tisza. Some blocks of flats exceed this height on its Eastern side. Family houses are generally below $5 \mathrm{~m}$. 


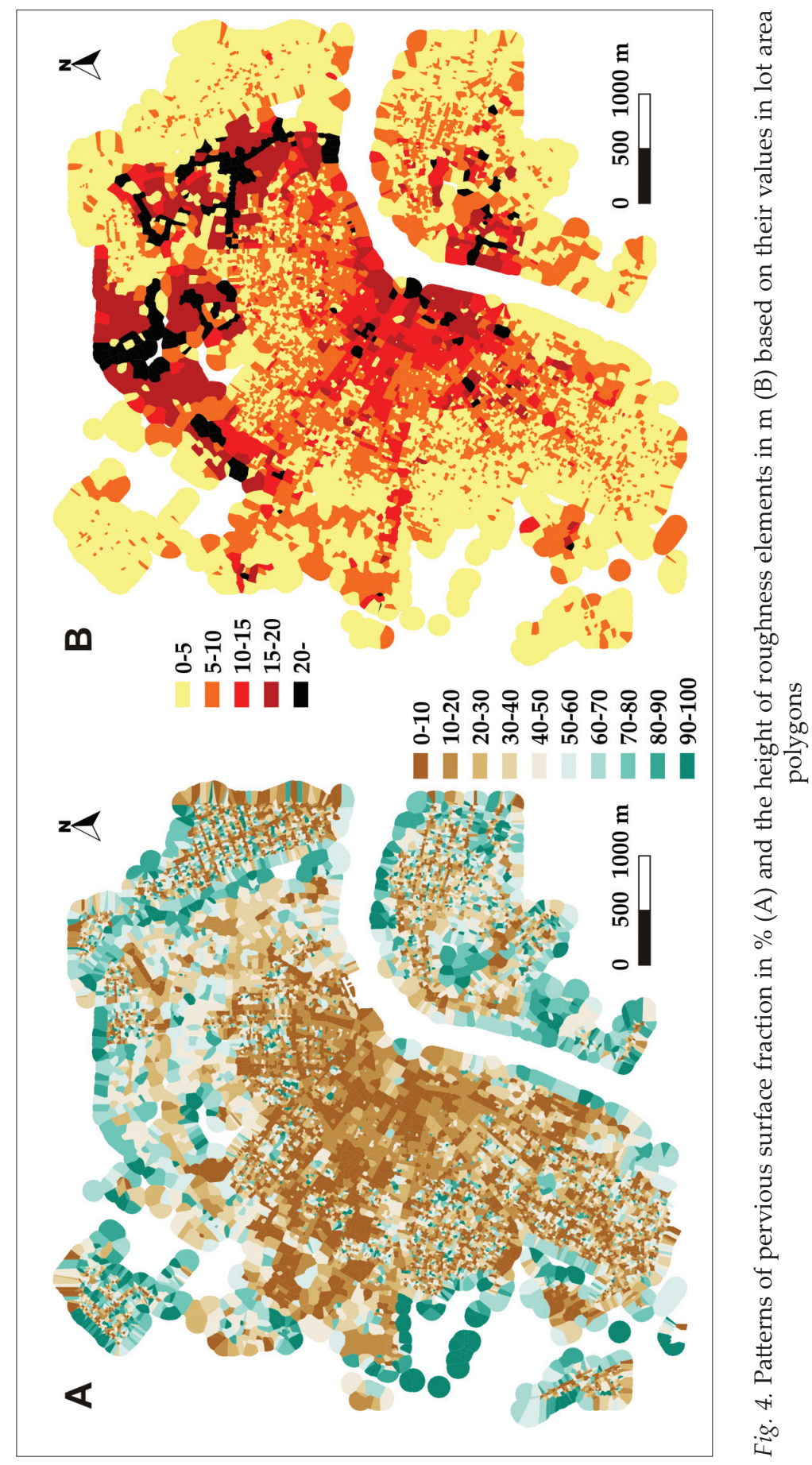


To get some verification, the PSF field was compared to the European soil sealing database published by EEA (2009) which is available with a spatial resolution of 20 metres. The patterns of the two PSF databases are very similar to each other, both represent the structure of the city well. The main difference between them is that the EEA database is less detailed.

\section{Aggregation and generalization of lot area polygons}

In line with the definition of LCZs, the lot area polygons classified into the same or similar LCZ classes (Figure 5. A) were merged into zones of hundreds of metres to several kilometres (Figure 5. B). In that case, we meet the minimum condition that the central point of an LCZ is at least 250 metres from the boundaries of the zone, such the relatively homogeneous area constitutes an area with a radius of 250 metres or greater. In order to get LCZ areas with appropriate size, the lot area polygons were aggregated into groups according to the following procedure.

First, the polygons were classified separately.

(1) From the obtained surface parameters, areal mean or percentage values were calculated to represent the polygons. Seven scores were assigned to each LCZ categories by polygons according to its fit (Figure 6) into the typical ranges given by STEWART, I.D. and OKE, T.R. (2012) and then they were summarized.

Two of the best fitting LCZ categories were assigned to every polygon (for each polygon the best was $\mathrm{LCZ}_{1}$ and the second best was $\mathrm{LCZ}_{2}$ ) if their scores were high enough. In the case of too low scores to fit to any LCZ categories, the polygon was considered unclassified.

Secondly, the lot area polygons were merged according to their LCZ categories and their locations related to each other.

(2) If a small polygon was located inside another polygon, the first LCZ class of the small polygon was set to the same as the outer polygon.

(3) If all of the neighbours of a polygon (except perhaps one of them) belonged to the same LCZ class, the class of the polygon was modified to the same as its neighbours.

(4) If a polygon did not have any neighbours in the same class, there were two cases: if there was a neighbour with the same $\mathrm{LCZ}_{1}$ like the polygon's $\mathrm{LCZ}_{2}$ or same $\mathrm{LCZ}_{2}$ like the polygon's $\mathrm{LCZ}_{1}$, the $\mathrm{LCZ}_{1}$ of the polygon was set to the same like its neighbour; if there was a neighbour with $L C Z_{1}$ category similar to the polygon's $\mathrm{LCZ}_{1}$ category, the $\mathrm{LCZ}_{1}$ of the polygon was modified to the $\mathrm{LCZ}_{1}$ of the neighbour.

In this context, 'similarity' refers to the condition when categories share certain properties. For example, the "compact mid-rise" or LCZ 2 class 


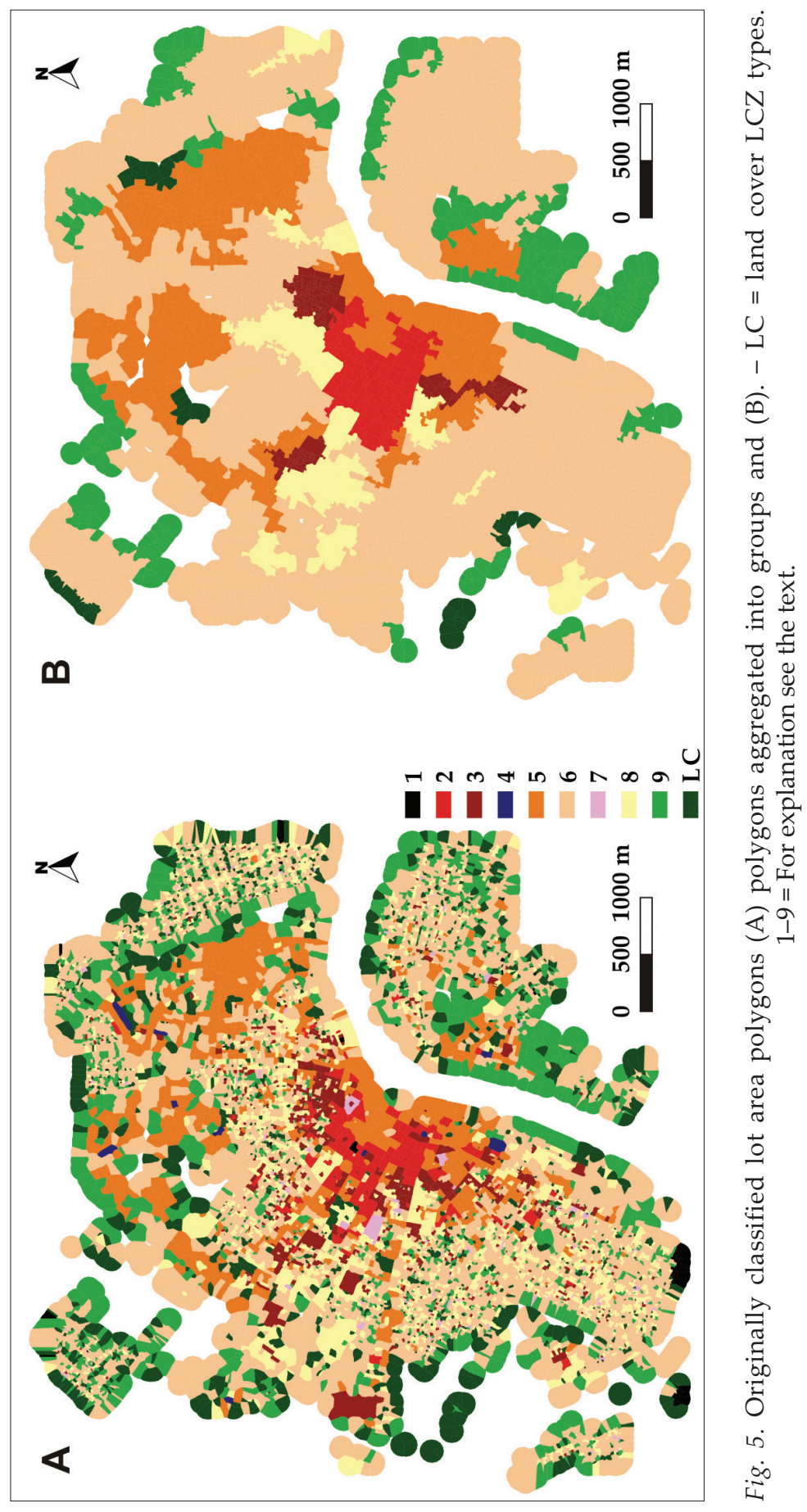




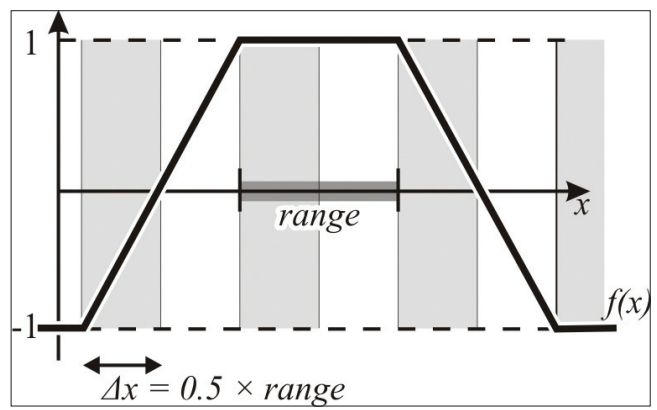

Fig. 6. Function of score assignment to a polygon according to its surface parameter values

is similar to the "compact highrise" (LCZ 1) and "compact lowrise" (LCZ 3) classes as they belong to the same density category. Likewise, the "open mid-rise" (LCZ 5) class can also be regarded as similar to LCZ 2 as they share the same height category.

(5) The LCZ categories of the remaining unclassified and non-aggregated polygons were defined as the most frequent classes of their neighbours.

Thirdly, the groups of adjacent polygons with a given LCZ category were investigated according to their spatial extension.

(6) If the area of a group covered at least one circle with a radius of $250 \mathrm{~m}$, it was regarded as an independent LCZ area.

(7) The polygons of groups which did not satisfy the criterion of the size were merged without considering their properties if they were adjacent. If the obtained group was large enough, the category of the group was set to the most frequent category of its parts; otherwise it was joined to one of the adjoining LCZ areas which had the largest number of contacting lot area polygons with it.

Finally, some manual corrections were made according to aerial photographs and our local knowledge of the area because of inadequate detachment of the zones. The most difficult task is the recognition of LCZ 8 (large low-rise) from the surface parameters. As a final result, we obtained several LCZ polygons in ESRI shape-file format suitable to produce maps or to extract spatial information as well.

\section{LCZ map of Szeged}

As the study area covered mostly the urbanized parts of Szeged, we focused on the "built" LCZ types. Due to the peculiarities of the city, it was to be expected prior to calculations that some "built" types did not occur there, namely the high-rise, lightweight low-rise and heavy industrialized zones (LCZ 1, 4, 7 and 10).

Aggregating the similar lot areas using the methods described above (the result is shown in Figure 5. B) and supplemented by the authors' local knowledge on the study area, a generalized LCZ map was obtained (Figure 7). 


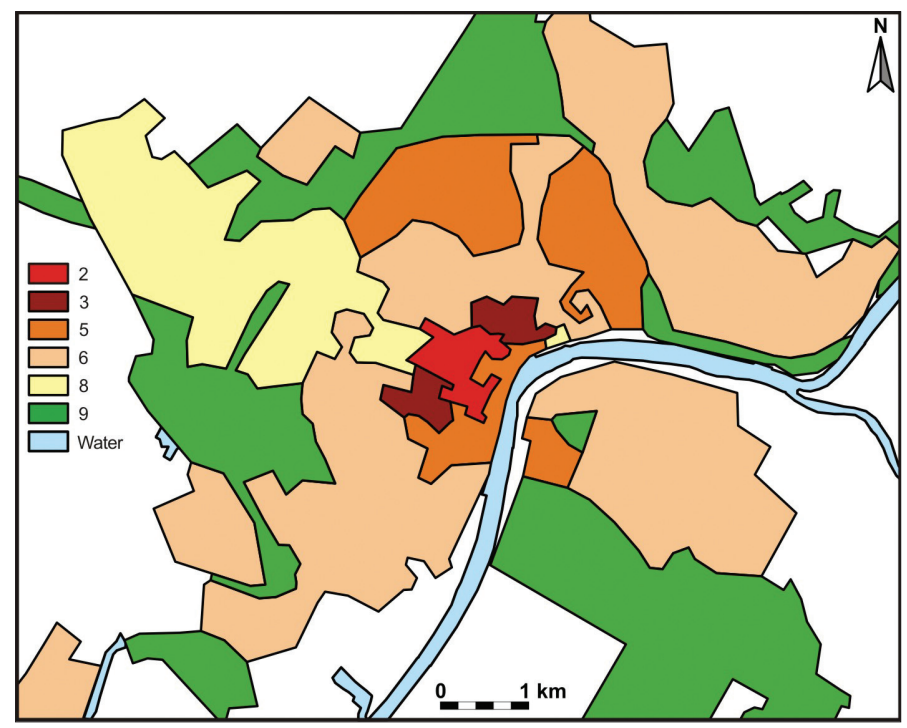

Fig. 7. The obtained LCZ map of Szeged. - LCZ 2 = compact mid-rise; LCZ 3 = compact low-rise; LCZ 5 = open mid-rise; LCZ 6 = open low-rise; LCZ 8 = large low-rise; LCZ 9 = sparsely built

During the generalization, the outlines of the polygons were simplified, some corrections and supplements were made according to aerial photographs and our local knowledge. For example, for our method the most challenging task was to separate LCZ 6 (open low-rise) and LCZ 8 (large low-rise) because of their similar properties. Water surfaces were not handled by our algorithms because they were located outside the lot area polygons for which the calculations were applied. These surfaces were digitized from the topographic map and the areas on the edges of the city without building database (and so without lot area polygons) were also digitized.

As the map shows, the remaining six "built" types cover the urbanized parts of Szeged (LCZ 2, 3, 5, 6, 8 and 9). Their extent and the number of constituent lot area polygons are different (Table 3 ) and altogether they cover an urban area of $46.50 \mathrm{~km}^{2}$ in Szeged.

Table 3. Areal extensions of the delineated LCZ zones

\begin{tabular}{c|c|c|c|c}
\hline \multirow{2}{*}{ LCZ zones } & \multirow{2}{*}{ Number of polygons } & Summarized & Mean & Largest \\
\cline { 3 - 5 } & & \multicolumn{3}{|c}{ area, $\mathrm{km}^{2}$} \\
\hline LCZ 2 & 176 & 0.63 & 0.63 & 0.63 \\
LCZ 3 & 248 & 0.67 & 0.33 & 0.35 \\
LCZ 5 & 796 & 4.35 & 1.18 & 1.98 \\
LCZ 6 & 9,303 & 5.63 & 2.80 & 5.22 \\
LCZ 8 & 798 & 15.32 & 2.96 & 5.87 \\
LCZ 9 & 566 & 1.93 & 5.71 \\
\hline
\end{tabular}




\section{Conclusions}

In this study we determined the LCZ types in Szeged which are representative for the urbanized area of the city using seven geometric, surface cover and radiative properties from the ten listed by STEWART, I.D. and OKE, T.R. (2012). The values of the properties were calculated by GIS methods developed for that purpose and for the appropriate classification of the selected areas, we used also our local knowledge about the districts of Szeged. As a result, six built LCZ types were distinguished and mapped in the studied urban area.

The developed method could be used in any urban area if the necessary input databases are available. The further steps in our investigation will be the application of the developed method in the LCZ mapping of Novi Sad (Serbia) and the discussion about the relation of the findings of this paper to the existing knowledge on an international level. Furthermore, we are going to acquire and utilize more GIS databases (e.g. EEA Urban Atlas) to have an even more detailed description of the urban surface.

Acknowledgement: The study was supported by the Hungary-Serbia IPA Cross-border Co-operation Programme (HUSRB/1203/122/166 - URBAN-PATH) and in the case of the second author by the TÁMOP 4.2.4.A/2-11/1-2012-0001 „National Excellence Program - Elaborating and operating an inland student and researcher personal support system convergence program" which project was subsidized by the European Union and cofinanced by the European Social Fund. In the case of the third author this research was realized in the frames of the Hungarian Scientific Research Fund (OTKA PD-100352) and the János Bolyai Research Scholarship of the Hungarian Academy of Sciences.

\section{REFERENCES}

Auer, A.H. 1978. Correlation of land use and cover with meteorological anomalies. Journal of Applied Meteorology 17. 636-643.

Bossard, M., Feranec, J. and Otahel, J. 2000. CORINE land cover technical guide - Addendum 2000. Technical report No 40. Copenhagen, European Environment Agency, 105 p.

Davenport, A.G., Grimmond, C.S.B., OKe, T.R. and Wieringa, J. 2000. Estimating the roughness of cities and sheltered country. Asheville, NC, Proceedings on $12^{\text {th }}$ Conference on Applied Climatology, 96-99.

EEA, 2009. FTSP Degree of soil sealing - Updated Delivery Report, European Mosaic, Issue 1.0. European Environmental Agency, 13 p.

ElLEFSEN, R. 1991. Mapping and measuring buildings in the canopy boundary layer in ten U.S. cities. Energy and Buildings 15-16. 1025-1049.

GÁL, T. and UNGER, J. 2009: Detection of ventilation paths using high-resolution roughness parameter mapping in a large urban area. Building and Environment 44. 198-206.

GÁL, T., Lindberg, F. and Unger, J. 2009. Computing continuous sky view factor using 3D urban raster and vector data bases: comparison and application to urban climate. Theoretical and Applied Climatology 95. 111-123.

Оке, T.R. 1987. Boundary Layer Climates. $2^{\text {nd }}$ edition. London-New York, Routledge, 435 p. 
Оке, T.R. 2004. Initial guidance to obtain representative meteorological observation sites. Geneva, WMO/TD No. 1250, 47 p.

RapidEye, 2012. Satellite Imagery Product Specifications, Version 4.1. 46 p.

Starks, P.J., Norman, J.M., Blad, B.L., Walter-Shea, E.A. and Walthall, C.L. 1991. Estimation of shortwave hemispherical reflectance (albedo) from bi-directionally reflected radiance data. Remote Sensing of Environment 38. 123-134.

SteWART, I.D. 2011. A systematic review and scientific critique of methodology in modern urban heat island literature. International Journal of Climatology 31. 200-217.

StEWART, I.D. and OKe, T.R. 2012. Local Climate Zones for urban temperature studies. Bulletin of the American Meteorological Society 93. 1879-1900.

Stewart, I.D. and OKe, T.R. 2009. A new classification system for urban climate sites. Bulletin of the American Meteorologial Society 90. 922-923.

Stewart, I.D., OKe, T.R. and Krayenhoff, E.S. 2013. Evaluation of the 'local climate zone' scheme using temperature observations and model simulations. International Journal of Climatology. DOI: 10.1002/joc.3746, 19 p.

Tasumi, M., Allen, R.G. and Trezza, R. 2008. At-Surface Reflectance and Albedo from Satellite for Operational Calculation of Land Surface Energy Balance. Journal of Hydrologic Engineering 13 (2): 51-63.

Tucker, C.J. 1979. Red and Photographic Infrared Linear Combinations for Monitoring Vegetation. Remote Sensing of Environment 8. 127-150.

WMO, 1983. Abridged final report, $8^{\text {th }}$ session. Geneva, Commission for Climatology and Applications of Meteorology,WMO, No. 600, 72 p. 


\title{
Ethnic map of Hungary 1941 + Ethnic map of present territory of Hungary 2001
}

\author{
Scale 1:500 000
}

\author{
Authors: KOCSIS, K. and BOTTLIK, ZS.
}

Geographical Research Institute, Hungarian Academy of Sciences, Budapest, 2009

The latest (eighth) piece of ethnic map series of the Carpathian Basin was an attempt to draft the changes that have taken place in the ethnic structure during the past five hundred years as well as to display its present state with the help of ethnic maps and a chart - in our case referring to the present-day territory of Hungary. On the front pages of our work consisting of two sheets ethnic maps of the present-day ter- ritory of Hungary are displayed with the help of piecharts, based on ethnic (2001) and mother tongue (1941) data. Populationthe terriand on proportional pie-charts provide information on torial distribution of the major ethnic groups Hungary in 1495, 1715,
$\begin{aligned} & 1784,1880,1910,1930,1941, \\ & \text { present-day territory of }\end{aligned}$
chart here explores the quantita-

Price: EUR 10.00 - For sale only in pairs!

Order: Geographical Institute RCAES HAS Library. H-1112 Budapest, Budaörsi út 45.

E-mail: magyar.arpad@csfk.mta.hu 